\title{
The role of mentalising in the management of violence
}

\author{
Gwen Adshead, Estelle Moore, Martin Humphrey, Claire Wilson \& James Tapp
}

\begin{abstract}
SUMMARY
Violence between people is a complex social phenomenon involving both social and individual psychological variables. Prevention of violence includes attention to risk factors for violence; but also the provision of interventions for those who have been violent to others. This article explores the evidence that failures of the mentalising process are a risk factor for acts of violence, especially in mental health service users; and describes the implementation of potential therapeutic programmes that seek to improve mentalising in individuals who pose a risk of serious violence to others.
\end{abstract}

\section{DECLARATION OF INTEREST}

None.

There are good reasons for mental health services to be concerned about violence. In 2004, the World Health Organization described violence as a major cause of mortality and morbidity, and identified it as an international public health problem (Krug 2002). In the health context, violence excludes civil or international armed conflict, but refers to the health impact of violence between individuals and groups, in the home or on the street, both fatal and non-fatal. Violence not only causes physical damage and death, it is also a potent risk factor for future violence, in terms of repeat perpetration and sometimes raising the risk that victims will become perpetrators.

Regarding mental health service planning, exposure to and injury by violence causes mental distress and disability which can be long term. Such health effects have cost implications both directly, in terms of the treatment needs of victims and perpetrators, and indirectly, in terms of the associated costs of general medical service utilisation and of the criminal justice processes that respond to violence.

It is sometimes suggested that violence is not a medical problem but a universal and inevitable feature of human behaviour. However, the actuarial evidence is against this. In most Anglophone/ European countries, violence is a comparatively rare form of criminal behaviour. In England and Wales, it constitutes only $20 \%$ of recorded crime, and rates of all forms of violence have been dropping over the past decade (Home Office 2009; Smith 2010). Homicide rates in England and Wales doubled between 1960 and 1980, but have been stable ever since, numbering about 600 annually (Taylor 1999). If we assume that 40 million people are physically able to commit a homicide, a subgroup of only 600-700 looks highly statistically deviant.

We suggest that the criminal justice data indicate that violence is a comparatively rare human behaviour, but the combination of its rarity and its disproportionately damaging effects requires explanation that can drive interventions.

\section{Risk factors for violence}

The World Health Organization (Butchart 2004) report into violence suggested that an ecological model which incorporates a variety of influences holds most explanatory power (Bronfenbrenner 1977; Fig. 1). In this model, individual psychological risk factors (including mental illness and personality disorder) are likely to be small but significant risk factors for violence, and will need attention from mental health services. Risk assessment and intervention to reduce the risk of violence are key quality indicators for most mental health services providers, and an essential part of the care programme approach (Maden 2007).

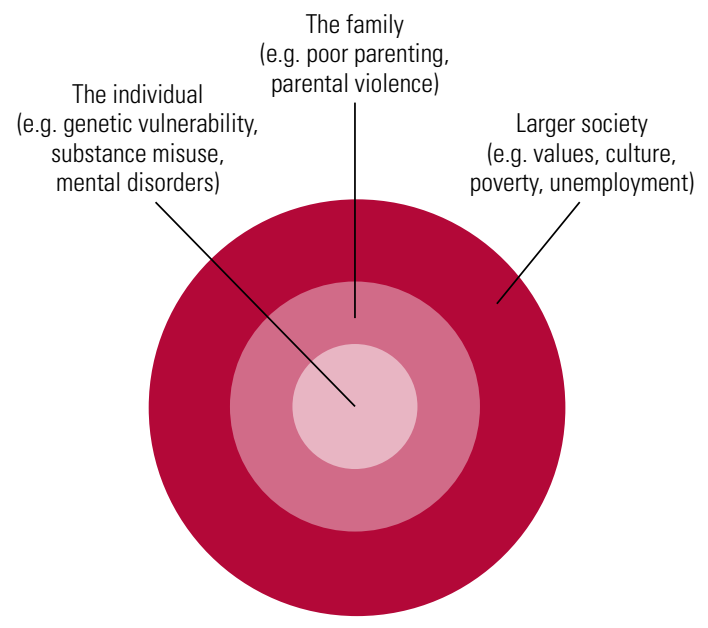

Ecological model of violence.

\section{ARTICLE}

Gwen Adshead and Martin Humphrey are consultant psychotherapists at Broadmoor Hospital, West London Mental Health NHS Trust. Estelle Moore and Claire Wilson are senior clinical psychologists in the Centralised Groupwork Service at Broadmoor Hospital. James Tapp is a research psychologist at Broadmoor Hospital.

Correspondence Gwen Adshead, Administrative Building, Broadmoor Hospital, Crowthorne, Berkshire RG45 7EG, UK. Email: gwen. adshead@wImht.nhs.uk 
There are other reasons why psychological approaches to understanding and changing violence-prone states of mind are important. First, the evidence about the nature of violence suggests that at least half of it arises in the context of a relationship between two people (Smith 2010). This is particularly true for children and infants under 1 year: infants are most at risk of being victims of homicide, and perpetrators are parents or in parental roles in $80 \%$ of such cases.

Second, severity of inflicted violence is affected by the relationship between perpetrator and victim; this appears to be the case for both sexual violence and homicide. Over $50 \%$ of homicides in England and Wales last year arose in the context of a quarrel, revenge or dispute between people who were well known to each other (Smith 2010), indicating that the perpetrator had thoughts and feelings about the victim in their mind before the violence began (i.e. they had a representation of the victim or their relationship with them in mind). Attention to the relationship, and the feelings/ thoughts associated with it, might be an important way to reduce the risk of violence.

Finally, it is now well established that certain types of disordered mental state - paranoid mental states, combined with disinhibition and impaired reality-testing - increase the risk of violence. Other risky psychological attitudes include lack of empathy, dehumanising people, and cruel and derogatory attitudes to the vulnerable. Psychological interventions that operate on how individuals 'see' others in their mind, and how they make judgements about reality and risk, could be helpful to the subgroup of psychiatric service users who present a risk to others.

A complexity for forensic mental services (especially secure residential settings) is that they must treat not only for mental health restoration, but also for risk reduction and violence prevention (Glorney 2010). It is not enough that patients feel better, they must also behave better (Adshead 2000). Therapeutic interventions, whether pharmacological, occupational or psychological, need to address the patient's capacity to cruelty and violence, as this will have been the reason they were admitted in the first place.

\section{Thinking of others: the social mind, empathy and mentalisation}

Anthropological study of human evolution and psychological development indicates that, like other primates, we are social animals who live in groups; and that our neocortex volume is related to the nature and extent of social relationships we need for survival (Dunbar 2003). This expanded neocortex is the substrate for our 'social' mind: the capacity to assess others as potential allies, mates, peers or predators. Unlike the other great apes and primates with whom we share so much genetic material, humans have extensive capacities for selfawareness and reflection on that awareness, and the capacity to imagine the state of mind of others.

This capacity to have mind-in-mind is also known as mentalisation - an individual's ability to recognise and imagine their own internal mental states and those of others (including beliefs, intentions, emotions and motivations) and, more importantly, understand and interpret one's own and others' actions as meaningful on the basis of these states (Allen 2008). Mentalisation includes a variety of meta-level operations of mind such as empathy, theory of mind, emotional recognition, metacognition and self-reflective function. It requires interpersonal abilities that are integral to a stable sense of self. It is not so much a capacity but a process which is going on in the mind at all times: it is about 'reading' other people's minds and also reflecting on one's own (known as selfreflective or reflective function; Fonagy 1997).

An important theoretical development has been the explicit link between early attachment relationships and the mentalising process in the mind of the child (Fonagy 2003a,b). Secure attachment in childhood is associated with the development of enhanced mentalisation processes, which in turn contribute to the homeostatic regulation of negative affect and arousal regulation (Schore 1996, 2001; Sarkar 2006). A person with limited or reduced mentalising processes will not be able to manage negative emotions such as normal anger, hatred and wishes to hurt. They are likely to become highly aroused very quickly and experience themselves as unable to think. Feelings of being overwhelmed with negative affects may lead to physical expressions of these affects, from shouting and damaging property, to self-harm and ultimately to harming others.

This escalating spectrum of acting out of negative affects may explain why it is unusual to find isolated acts of violence occurring de novo. Most people with histories of acts of violence have escalated from verbal abuse and property damage to self-harm or harm to others; and there is some evidence that those who self-harm have a small but real increased risk of acting violently, and vice versa. The concept of a spectrum of acting out behaviours (property $\rightarrow$ self $\rightarrow$ others) would also explain why national trends in suicide and homicide tend to be very similar (Gilligan 2011).

The mentalising process is essential to two other areas of mental function: self-other discrimination 
and self-other security. First, reflective function entails the capacity to distinguish one's own mind from that of another; it allows a thinker to see other minds as real, and makes and maintains the boundary between different internal worlds. People with poor reflective function (e.g. individuals with borderline personality disorder) find it difficult to distinguish between self-states and other states; instead, there is enmeshment between self and others which gives rise to severe anxiety (Bender 2007). Such blurring of self-other boundaries has been found to be associated with violence to others in the context of psychotic mental disorders (Link 1994).

Second, reflective function enables a person to attach to others safely; it is crucial to being prosocial. As suggested above, it is an aspect of the social mind that evolved out of our identity as group animals and our need to communicate over time and place. Without the ability to 'read' other minds accurately, other group members may be identified as either 'predator' or 'prey', or (worse) something that oscillates between. There will be no opportunity to make attachment bonds to peers which allow groups to form that enhance safety and social function; lack of reflective function may result in social exclusion, which itself results in increased mortality and early death (House 1988).

A measure of reflective function has been developed on the basis of attachment narratives. (Fonagy 1998). Individuals who have high levels of mentalising function are better able to process negative affects, so that they do not overwhelm the mind and stop thought. In contrast, those who have low mentalising function are overwhelmed by negative affects and unable to metabolise them effectively. The link between poor mentalising function and affect dysregulation has been made most clearly in relation to borderline personality disorder (Bateman 2006; Levy 2006). The characteristic 'affect storms' of borderline personality disorder are accompanied by cognitive distortions (often of parapsychotic intensity) and acts of violence (usually self-directed).

\section{Violence as failure of mentalising: releasing the locks on violence}

The psychological and psychiatric study of violence explores the contribution of the individual's internal psychological experience to risk. In this sense, an individual offender's psychological or psychiatric state is like the last number of a bicycle lock: acting as the final risk factor which, when combined with others, 'unlocks' the inhibitory mechanisms that prevent violence exploding from the internal to the external world (Blair 2003).
In this section we review the evidence that low levels of mentalising enhance the risk of violence. There are two principal ways to address this:

1 to look at levels of violence in people who may be expected to have poor reflective function owing to attachment insecurity; and

2 to measure reflective function in violent offenders.

\section{Violence in people with insecure attachments who may be mentalising poorly}

Understanding violence within a mentalising framework entails examining the association between early maladaptive attachment styles (Shonk 2001) and subsequent behavioural responses to negative interpersonal interactions (Bateman 2008a). The attachment paradigm might be useful for relational violence in particular (Pfäfflin 2004). The majority of victims of severe violence are related to the perpetrator by attachment relationships: partners, ex-partners, parents, friends or children (Smith 2010). Interestingly, a significant subgroup of forensic patients are admitted to secure care because of attacks on professional carers with whom they may have had a professional attachment (Adshead 1998).

Attachment systems are activated at times of distress, arousal and threat (Bowlby 1960) and violent behaviours are known to be more likely at such times. Individuals with insecure attachments are known to have poor affect regulation (Schore 2002), and acts of violence are usually described as being affectful or affectless (Meloy 2006). Crime scene indicators often suggest either explosions of extreme, disorganised and disproportionate affect, or highly controlled violence (Canter 2004). Such outbursts suggest a disastrous failure to mentalise negative affects such as shame, hatred, fear or anger in the context of interpersonal conflict and/or high negative expressed emotion (Gilligan 2002).

However, the evidence that insecure attachment alone is a highly influential risk factor for violence is limited. Insecure attachment is an expected finding in $40 \%$ of the community as a whole (van Ijzendoorn 2003) and is therefore too common to account causally for violence as a whole. Selfdirected violence has been described in association with personality disorder, where insecurity of attachment is a feature of childhood history, especially borderline personality disorder where enmeshed attachment patterns are commonly found (Levy 2005). However, only a minority of people with personality disorder, even antisocial personality disorder, are violent to others 
(Duggan 2009). In a recent study of attachment in prisoners, insecure attachment was not associated with convictions for violence, although anxious attachment was associated with intimate partner violence (Hansen 2011).

Insecurity of attachment may only be a risk factor for violence in certain circumstances or under certain conditions. Disorganised attachment in childhood is associated with the development of more severe clinical psychiatric disorders (van Ijzendoorn 2003), although it has not yet been established that the severity of any psychiatric disorder is a risk factor for violence.

Maltreated children are at increased risk of developing conduct disorder, which in turn puts them at risk of antisocial behaviour in youth and early adulthood (Kim-Cohen 2006, 2009): disorganised attachment may be the mediator, although this is also not established.

Studies of violence trajectories in youth suggest that there is a subgroup of children who show callous and unempathic attitudes from an early age, and later display violent behaviour (Wootton 1997). However, it is still not clear whether the lack of the mentalising process is operative here or whether there is a relationship between disorganised attachment, poor mentalising and callous and unempathic attitudes.

\section{Insecure attachment and failure of mentalising in violent populations}

If failure of the mentalising process is relevant to violence commission, then we might expect to find evidence in violent offenders of either:

1 highly insecure attachment histories; or 2 low levels of reflective function.

There is now a considerable evidence base of studies that show higher levels of insecure attachment in violent offenders compared with community norms (see Pfäfflin 2004 for review; Bakermans-Kranenburg 2009). In the general population, insecurity of attachment is found in $40 \%$ of the population, but in forensic settings, this is closer to 60-70\% (Frodi 2001; Adshead 2004; Levinson 2004; Bogaerts 2005).

This level of insecure attachment is unsurprising, given the excess levels of childhood adversity and trauma in forensic populations, both in prison and secure psychiatric settings. Offenders in prison or forensic secure care are more likely to have been separated from their parents, severely physically maltreated or neglected, and put into Social Services' care before age 15 years than their non-offending community counterparts. Abuse and neglect are typically reported in 30\% of
BOX 1 The most common forms of insecure attachment

- Enmeshed or preoccupied (E)

- Dismissing or avoidant (D)

- Cannot classify (CC)

(Hesse 2008)

most general populations internationally (Kessler 2010 ), but rates of $60-70 \%$ are the norm in forensic settings (Coid 1992; Heads 1997; Weeks 1998).

\section{Types of insecure attachment}

A number of types of insecure attachment may be relevant to poor mentalising (Box 1). Among these, type CC is a highly disorganised adult attachment pattern in which both enmeshed (E) and dismissing (D) attachment styles are mixed together in a chaotic way (Hesse 2008). Type CC is commonly found in clinical populations (Bakermans-Kranenburg 2009). Individuals with CC attachment status may be intermittently in hostile, helpless, frightened or frightening states of mind (Lyons-Ruth 1999; Hesse 2000). In addition, individuals may have unresolved (U) attachment representations in relation to loss or trauma, which result in unpredictable and disturbing lapses of reasoning or thinking when reminded of the trauma. Unresolved traumatic affects (such as may be present in post-traumatic stress disorder) can cause brief and discrete failures of mentalisation (George 1985).

The patterns of insecure attachment found in forensic populations are different from those in other clinical populations. Most studies of attachment in clinical populations find high levels of $\mathrm{E}$ and/or CC attachment, whereas studies of attachment in offenders typically find high levels of D attachment (Adshead 2004: p. 152). This is a pattern of thinking about attachment relationships in which neediness and vulnerability are denied, disavowed or even derogated (Hesse 2008). Dismissing attachment organisation may be relevant to the commission of violent acts that entail derogatory attitudes to neediness, dependence and pain; in fact, it may be difficult to commit such acts without such derogatory attitudes.

The other types of insecure attachment are less common in forensic settings than in other clinical groups. This may be an artefact of measurement or may reflect that measurement of attachment is taking place in a setting where people are frightened and defensive, and reluctant to show 
vulnerability. We might hypothesise that the CC category would be more common in forensic psychiatric populations who are mentally unwell as well as violently antisocial, but this has not yet been shown to be the case.

\section{Self-reflective function}

If violence is related to poor mentalising capacity, then we should expect to find low levels of mentalising function in violent offenders as measured by self-reflective function. However, only one study has specifically looked at reflective function in violent offenders. Levinson $\&$ Fonagy (2004) measured reflective function in a sample of men imprisoned for a variety of offences and found that violent offenders had lower levels of reflective function than non-violent offenders. Bateman \& Fonagy (2008b) have also found low levels of reflective function in individuals with selfdirected violence and they argue that reductions in such behaviour are mediated by therapies that improve mentalisation and reflective function, such as mentalisation-based treatment (MBT) and transference-focused therapy (Levy 2006). However, the relationship between self-directed violence (in terms of self-harm) and other directed violence is not clear: Gilligan's work (2011) finds a link between completed suicide and homicide rates, not self-harming behaviours, that are the focus of most treatment interventions. In addition, the Levinson \& Fonagy study has yet to be replicated.

\section{Linking mentalisation failure and violence}

The attachment and mentalisation model of mind would suggest that people with highly disorganised attachment systems may be at risk of failing to mentalise when their attachment histories are triggered. These difficulties are essentially a diminished view of the self in relation to others. Feelings of shame could activate this temporary state of mind. Shame has been associated with antisocial and violent behaviours and might have some explanatory value in relation to fragile selfconcepts and humiliation (Gilligan 2002). Shame has been conceptualised in evolutionary terms as relating to threatened perceptions of the self in the social hierarchy (Gilbert 2005).

\section{High v. low affect}

The question of affect dysregulation and violence is complicated. Violent offenders may be divided into a high-affect, impulsive and hyperaroused group on the one hand, and a low-affect, hypoaroused and unemotional group on the other (Meloy 2006). The high-affect group resemble patients with borderline personality disorder who repeatedly harm themselves, leading Bateman $\&$ Fonagy (2009) to propose that a subgroup of people with antisocial personality disorder resemble people with borderline personality disorder, who can oscillate between reasonable reflective function and temporary losses of mentalising function with consequent fragmented self-experience and frightening affect storms. Such unstable oscillations of mental state are characteristic of disorganised attachment processes (van Ijzendoorn 2003), and in such a state it may be impossible to make coherent (and safe) judgements about other people's minds.

Conversely, the low-affect group seem to havelittle concern for anyone's feelings, including their own. Indeed, there is some evidence that some violent offenders are satisfied by seeing fear or distress in others, and experience a sense of mastery and control in the presence of others' distress. Meloy (2006) describes this group as predatory; and this group do seem to function socially as if they were hunters and other people were (literally) 'fair game'. Specifically, this group of violent offenders also appear to experience contempt and derogation for vulnerability, neediness and distress; even if this does reflect unconscious projection of vulnerability, it reflects a conscious wish to hurt and control. Such states of mind are often seen as characteristics of psychopathy: a specific form of personality disorder in which meanness and cruelty to vulnerable others is a key factor (Patrick 2009). It is possible to see a link between the dismissing derogating attachment style (which is found in only a small subgroup of the population) and the subgroup offviolent offenders who are specifically cruel and humiliating to people who are vulnerable and distressed, and who score highly on psychopathy measures (Frodi 2001).

Not only is some violence both predatory and highly controlled: some types of violence and cruelty to others suggest that the perpetrator's reflective function in terms of assessing the victim's intentions is particularly high. Reflective function may be high when empathy is low: studies of military atrocities suggest that there is no necessary connection between these two factors (Burleigh 1995; Browning 2001). It might be argued that in these men and women, the affective disturbance is unconscious but still present: what is consciously detectable is a disavowal of affect, characteristic of dismissing attachment systems (Bowlby 1960).

A further subgroup of individuals becomes aroused and affectful only when they see others' distress; this arousal may become sexualised. This 
subgroup may have something in common with people who self-harm who describe emptiness, numbness and affectlessness until they harm themselves.

\section{Failure of empathy and reduced theory of mind}

The link between mentalising and violence is also complex because some accounts of mentalising include psychological capacities such as empathy and the capacity to conceive of other minds (ChoiKain 2008). Failure of empathy is a key feature of violent offending (Joliffe 2006), so prima facie this would indicate a failure of mentalising capacity. However, studies of empathy in offenders have mixed findings in terms of lack of empathy (Joliffe 2006): not all violent offenders demonstrate lack of empathy and some offenders may actually score highly on empathy.

There has been similar theoretical interest in whether violent offenders show reduced theory of mind capacity (as in autism); the hypothesis being that people with theory of mind deficits would not recognise or be disturbed by others' distress. The evidence here again is conflicting: some offenders do show theory of mind deficits but others do not. Even offenders who score highly on psychopathy measures (and who are therefore at increased risk of acting violently) do not necessarily show theory of mind deficits (Richell 2003; Dolan 2004).

The two types of violence (high-affect and lowaffect) mirror the current discussions about two different neuronal systems underlying empathy and theory of mind. Blair (2005) distinguishes emotional empathy and cognitive empathy, with the latter being akin to theory of mind; and there is evidence that there are two different systems involving the amygdala and orbitofrontal cortex that underpin empathic responses (Shamay-Tsoory 2009, 2010).

Another helpful contribution, drawing on social cognitive neuroscience, is Lieberman's (2007) distinction between internally and externally focused aspects of theory of mind. Internally focused processes are activated by mentalising aspects of the self and others' thoughts, feelings and experience - their 'interior world'. On the other hand, the external focus is on physical and visible features; the non-mentalising aspects of theory of mind. In reviewing the basis for a mentalisation-based approach for people with borderline personality disorder, Fonagy $\&$ Luyten (2009) refer to this group as having difficulty in tasks that require a direct focus on mental interiors, while being adept at understanding external characteristics. The same distinction may apply to people with affectful violence.

\section{Psychosis}

The failure-to-mentalise model of violence also needs to explain the contribution of psychosis to violence-prone mental states. Psychosis increases the risk of violence in a number of ways: by simple disinhibition, failure of good-quality judgement when reality is distorted, or rational response to perceived (but irrational) threat (Link 1994). Severe affective dysregulation may lead to psychotic states (and vice versa), and failures of metacognition are well documented in psychotic states (Dimaggio 2008). This function is distinct from mentalisation, and although it is tempting to assume that psychosis reduces mentalising function, this has not yet been demonstrated.

\section{Improving mentalisation with violent individuals: a pilot project in a high secure hospital}

The effectiveness of MBT in borderline personality disorder is of therapeutic significance to those treating violent states of mind, especially in terms of reduction of impulsive violence. The overall structure of MBT provides a space in which the objective is to think about how thoughts and feelings dictate actions and to identify where errors in this process occur that result in problematic reactions. In research trials, MBT techniques that aim to improve reflective function have been shown to decrease affect storms, improve abilities to self-reflect and reduce self-harming behaviours, improvements maintained over the longer term (Levy 2006; Bateman 2008a,b).

We set up a pilot MBT group to test its acceptability to patients and to see whether it is possible to replicate the technical format of MBT in long-stay residential secure care. We selected as potential group members men who had struggled with high levels of episodic violence throughout their lives, including within the hospital. We also selected men who had a variety of severe personality psychopathology: this is the norm in specialist and high secure settings (Blackburn 2003; Yang 2010) (Table 1). We made it clear to participants that this was a pilot and that its aim was to increase their capacity to manage negative affects and to improve reality-testing and perspective-taking in their dayto-day lives. We used a variety of interventions aimed at improving mentalising function (Allen 2008), including psychoeducational sessions and film clips as well as reflective sessions.

Nine patients were referred for the first group; one patient declined to participate during the assessment process and two dropped out of the group at a later stage. In terms of diagnoses, four 


TABLE1 Mentalisation-based treatment pilot study
attenders in a high secure hospital
\begin{tabular}{|lc|}
\hline Characteristics & $\boldsymbol{n}$ \\
\hline Ethnicity & \\
White & 8 \\
$\quad$ Black and minority ethnic & 1 \\
\hline Primary diagnoses & \\
Paranoid schizophrenia & 4 \\
Dissocial personality disorder & 2 \\
Emotionally unstable personality disorder & 1 \\
Mixed and other personality disorder & 2 \\
\hline Offences leading to admission & \\
Murder & 1 \\
Manslaughter & 2 \\
Violence & 2 \\
Adult sexual offences & 2 \\
Other offences (e.g. threats to kill) & 2 \\
\hline
\end{tabular}

had a primary diagnosis of paranoid schizophrenia, but comorbid personality dysfunction was also present in these men, although they did not meet full criteria for diagnosis. Similarly, the men with primary personality disorder diagnoses also had histories of psychosis. Such diagnostic comorbidity is typical of high secure hospital patients (Blackburn 2003).

Forty-eight group sessions were conducted between January 2008 and March 2009. There was full attendance at 31 of these meetings, with reasons for non-attendance including feeling unwell or competing appointments (e.g. visitors to the hospital).

Three trained facilitators were present at the sessions most weeks, but on occasion the group ran with two facilitators. The range of techniques within the MBT literature aimed at improving mentalising function (Allen 2008), including introductory psychoeducational sessions to prepare participants to get the most out of the group meetings and reflective individual sessions. We rated the adherence of the group therapists to the MBT model using guidance published by Bateman \& Fonagy (2004).

\section{Preliminary findings}

The pilot project showed the importance of the group process for improving mentalising. Group membership and the group process makes multiple perspective-taking inevitable as a psychological exercise. Group activity does not stimulate the attachment system in the same way as one-to-one sessions, especially for those individuals who had suffered abuse by caregivers. Multiple mirroring is possible, which may be relevant to empathic function through imitation and the stimulation of mirror neurons (Gallese 2001, 2004). In the forensic context, group work also offered the possibility of belonging to something again and connecting to others - of being 'social'. Such a view fits with other accounts of the importance of group work with offenders (Marshall 2010).

Self-report and behavioural data-based measures were collated at 12 and 18 months (effectively mid- and post-group) and followed up at 6 months post-group. Three participants reported improvements in mindfulness, scoring in a non-clinical normative range of functioning post-group. However, no significant change was reported.

We noted more functional defence style (as measured on the Defense Style Questionnaire: Andrew 1993) in one participant, and clinically and reliably significant change across all scales of the Inventory of Interpersonal Problems (IIP-64; Horowitz 2000) in another. Where any improvement in interpersonal problem-solving was endorsed, this was maintained at follow-up and beyond the group. The majority of the group graduates reported significant improvements overall in relation to interpersonal problems.

Interpersonal relationships are a risk factor for violent incidents taking place within the hospital so we looked for any changes in incident data in terms of behaviour within the hospital. There was a low base rate of within-hospital incidents for this pilot group, probably due to careful selection from the early stages of referral by the clinical teams. No incidents were reported for three of the six participants. However, one patient was involved in an incident in which he directed physical violence against a fellow patient. It was possible to discuss this incident in the group session and explore the process of mentalising and its relationship to the use of aggression - perhaps an example of the direct portability and use of the model within the forensic context.

Two men dropped out of the group, but the rest group completed the year-long programme. At the time of writing, all the men have moved to a pre-discharge care pathway, including those who had been most violent most often. We did not specifically measure reflective function, so we cannot say whether improved mentalising has contributed to improved function in the hospital. It may be that, for individuals who struggle with so much psychological disability, any intervention that takes thinking seriously and encourages self-reflection (not just learning) will produce behavioural results.

\section{Implications and future directions}

In summary, results are inconclusive and questions remain about the role of mentalisation failure as a risk factor for violence. It may be 
relevant for only a subgroup of violent offenders, i.e. those with high affectivity and impulsivity (e.g. borderline personality disorder). One may therefore imagine that a typical individual will be a man who has been socially isolated, misusing substances and antisocial from late childhood. Such a man will almost certainly struggle to manage negative affects and is likely to be diagnosed with borderline personality traits. If he is psychologically 'threatened' with a perceived loss, he will be overwhelmed with feeling and may fail to mentalise. This loss of mentalising capacity will act as the final 'number' in the internal locking system and violence can then erupt. Once the affect storm is over, the offender patient may feel and behave calmly, and may only be violent again when the particular combination of circumstances is activated.

For this group of violent offenders, there would seem to be sufficient evidence to be offering mentalisation-based interventions, ideally in the form of controlled treatment trials. However, there still remains the puzzle of how best to intervene with violent men and women who seem to have high levels of mentalising function. The terrible and tragic case of Anders Breivik, an apparently normal young man who killed 77 people in Norway, makes the point of how urgently we need to find ways of understanding and managing cruel and unusual states of mind.

\section{References}

Adshead G (1998) Psychiatric staff as attachment figures. Understanding management problems in psychiatric services in the light of attachment theory. British Journal of Psychiatry 172: 64-9.

Adshead G (2000) Care or custody: ethical dilemmas in forensic psychiatry. Journal of Medical Ethics 26: 302-4.

Adshead G (2004) Three degrees of security: attachment in forensic institutions. In A Matter of Security: The Application of Attachment Theory to Forensic Psychiatry and Psychotherapy (eds F Pfäfflin, G Adshead): 147-66. Jessica Kingsley Publishers.

Allen JG, Fonagy P, Bateman A (2008) Mentalising in Clinical Practice. American Psychiatric Press.

Andrew G, Singh M, Bond M (1993) The Defense Style Questionnaire. Journal of Nervous and Mental Disease 18: 246-56

Bakermans-Kranenburg MJ, van ljzendoorn M (2009) The first 10000 Adult Attachment Interviews: distribution of adult attachment representations in clinical and non-clinical groups. Attachment and Human Development 11: 223-63.

Bateman A, Fonagy P (2006) Mentalization Based Treatment for Borderline Personality Disorder: A Practical Guide. Oxford University Press.

Bateman AW, Fonagy P (2008a) Comorbid antisocial and borderline personality disorders: mentalization-based treatment. Journal of Clinical Psychology 64: 181-94.

Bateman A, Fonagy P (2008b) 8-year follow-up of patients treated for borderline personality disorder: mentalization-based therapy versus treatment as usual. American Journal of Psychiatry 165: 631-8.

Bateman A, Fonagy P (2009) Randomised controlled trial of outpatient mentalization-based therapy versus structured clinical management for borderline personality disorder. American Journal of Psychiatry 166 : 1355-64.

Bender DS, Skodol A (2007) Borderline personality as self-other representational disturbance. Journal of Personality Disorders 21: 500-17.

Blackburn R, Logan C, Donnelly J, et al (2003) Personality disorders, psychopathy and other mental disorders: co-morbidity among patients in English and Scottish high security hospitals. Journal of Forensic Psychiatry \& Psychology 14: 111-37.

Blair RJR (2003) Neurobiological basis of psychopathy. British Journal of Psychiatry 182: 5-7.

Blair RJR (2005) Responding to the emotion of others: dissociating forms of empathy through the study of typical and psychiatric populations. Consciousness and Cognition 14: 698-718.

Bronfenbrenner U (1977) Towards an experimental psychology of human development. American Psychologist 32: 513-31.

Bogaerts S, Vanheule S, Declerq F (2005) Recalled parental bonding, adult attachment style and personality disorders in child molesters: a comparative study. Journal of Forensic Psychiatry \& Psychology 16 : 445-58.

Bowlby J (1960) Attachment and Loss, Vol.1. Attachment. Hogarth Press.

Browning C (2001) Ordinary Men: Reserve Police Battalion 11 and the Final Solution in Poland. Penguin.

Burleigh M (1995) Death and Deliverance: 'Euthanasia' in German 1900-1945. Cambridge University Press.

Butchart A, Phinney A, Check P, et al (2004) Preventing Violence: $A$ Guide to Implementing the Recommendations of the World Report on Violence and Health. Department of Injuries and Violence Prevention, World Health Organization.

Canter D, Alison J, Alison E, et al (2004) The organised/disorganised typology of serial murder: myth or model? Psychology, Public Policy and the Law 10: 293-320.

Coid J (1992) DSM-III diagnosis in criminal psychopaths: a way forward. Criminal Behaviour and Mental Health 2: 78-94.

Choi-Kain LW, Gunderson JG (2008) Mentalization: ontogeny, assessment, and application in the treatment of borderline personality disorder. American Journal of Psychiatry 165: 1127-35

Dimaggio G, Lysaker PH, Carcione A, et al (2008) Know yourself and you shall know the other... to a certain extent: multiple paths of influence of self-reflection on mindreading. Consciousness and Cognition 17: 778-89

Dolan M, Fullam R (2004) Theory of mind and mentalizing ability in antisocial personality disorders with and without psychopathy. Psychological Medicine 34: 1093-102.

Duggan C, Howard RC (2009) The 'functional link' between personality disorder and violence: a critical appraisal. In Personality, Personality Disorder and Violence (eds M McMurran, RC Howard): 19-37. John Wiley.

Dunbar RIM (2003) The social brain: mind, language and society in evolutionary perspective. Annual Review Anthropology 32: 163-81.

Fonagy P (2003a) Towards a developmental understanding of violence. British Journal of Psychiatry 183: 190-2.

Fonagy $\mathrm{P}(2003 \mathrm{~b})$ The developmental roots of violence in the failure of mentalization. In A Matter of Security: The Application of Attachment Theory to Forensic Psychiatry and Psychotherapy (eds F Pfäfflin, G Adshead): 13-56. Jessica Kingsley Publishers.

Fonagy P, Target M (1997) Attachment and reflective function: their role in self-organisation. Development and Psychopathology 9: 679-700.

Fonagy P, Target M, Steele H, et al (1998) Reflective-Functioning Manual, version 5.0, for Application to Adult Attachment Interviews. University College London.

Fonagy P, Luyten P (2009) A developmental, mentalisation based approach to the understanding and treatment of borderline personality disorder. Development and Psychopathology 21: 1355-81. 
Frodi A, Dernevik M, Sepa A, et al (2001) Current attachment representations of incarcerated offenders varying in degrees of psychopathy. Attachment and Human Development 3: 269-83.

Gallese V (2001) The 'Shared manifold' hypothesis: from mirror neurons to empathy. Journal of Consciousness Studies 8: 33-50.

Gallese V, Keysers C, Rizzolatti G (2004) A unifying view of the basis of social cognition. Trends in Cognitive Sciences 8: 396-403.

George C, Kaplan N, Main M (1985) Adult Attachment Interview. Department of Psychology, University of California at Berkeley, USA.

Gilbert P (2005) Bullying among prisoners: an evolutionary and psychosocial approach. In Bullying among Prisoners: Innovations in Theory and Research (ed J Ireland): 176-200. Willan.

Gilligan J (2002) Violence: Reflections on our Deadliest Epidemic. Jessica Kingsley Publishers.

Gilligan J (2011) Why Some Politicians are More Dangerous than Others. Polity Press.

Glorney E, Perkins D, Adshead G, et al (2010) Domains of need in a high secure hospital setting: a model for streamlining care and reducing length of stay. International Journal of Forensic Mental Health 9: $138-48$.

Hansen AL, Waage L, Eid J, et al (2011) The relationship between attachment, personality and antisocial tendencies in a prison sample: a pilot study. Scandinavian Journal of Psychology 52: 268-76.

Heads T, Taylor P, Leese M (1997) Childhood experiences of patients with schizophrenia and a history of violence: a special hospital sample. Criminal Behavior and Mental Health 7: 117-30.

Hesse E, Main M (2000) Disorganized infant, child and adult attachment: collapse in behavioral and attentional strategies. Journal of the American Psychoanalytic Association 48: 1097-127.

Hesse E (2008) The adult attachment interview: protocol, method of analysis, and empirical studies. In Handbook of Attachment (eds J Cassidy, PR Shaver): 552-98. Guilford.

Home Office (2009) Crime in England and Wales 2007-2008. Ministry of Justice.

Horowitz LM, Alden LE, Wiggins JS, et al (2000) Inventory of Interpersonal Problems Manual. The Psychological Corporation.

House JS, Landis KR, Umberson D (1988) Social relationships and health. Science 241: 540-5.

Joliffe D, Farringdon DP (2006) Development and validation of the Basic Empathy Scale. Journal of Adolescence 29: 589-611.

Kessler RC, Mclaughlin KA, Greif Green J, et al (2010) Childhood adversities and adult psychopathology in the WHO World Mental Health Surveys. British Journal of Psychiatry 197: 378-85.

Kim-Cohen J, Caspi A, Taylor A, et al (2006) MAOA, maltreatment and gene-environment interaction predicting children's mental health: new evidence and a meta-analysis. Molecular Psychiatry 11: 903-13.

Kim-Cohen J, Cicchetti D, Rogosch F, et al (2009) Child maltreatment and trajectories of personality and behaviour functioning: implications for development of personality disorder. Development and Psychopathology 21: 889-912.

Krug EG, Dahlberg LL, Mercy JA, et al (eds) (2002) World Report on Violence and Health. World Health Organization.

Levinson A, Fonagy $P$ (2004) Offending and attachment: the relationship between reflective awareness and offending in a prison population. Canadian Journal of Psychoanalysis 12: 225-51.

Levy K, Meehan B, Weber M, et al (2005) Attachment and borderline personality disorder: implications for psychotherapy. Psychopathology 38: $64-75$.

Levy KN, Meehan KB, Kelly KM, et al (2006) Change in attachment patterns and reflective function in a randomized control trial of transference-focused psychotherapy for borderline personality disorder. Journal of Consulting and Clinical Psychology 74: 1027-40.

Lieberman MD (2007) Social cognitive neuroscience: a review of core processes. Annual Review of Psychology 58: 259-89.
Link B, Stueve A (1994) Psychotic symptoms and the violent illegal behaviour of mental patients compared with community controls. In Violence and Mental Disorder: Developments in Risk Assessment (eds J Monahan, H Steadman): 147-60. University of Chicago Press.

Lyons-Ruth K, Bronfman E, Atwood G (1999) A relational-diathesis model of hostile-helpless states of mind: expressions in mother-infant interaction. In Attachment Disorganization (eds J Solomon, C George): 33-70. Guilford Press.

Maden T (2007) Treating Violence: A Guide to Risk Management in Mental Health. Oxford University Press.

Marshall W, Burton D (2010) The importance of group processes in offender treatment. Aggression \& Violent Behaviour 15: 141-9.

Meloy JR (2006) Empirical basis and forensic application of affective and predatory violence. Australian and New Zealand Journal of Psychiatry 40: 539-42.

Patrick C, Fowler CD, Krueger RF (2009) Triarchic conceptualisation of psychopathy: developmental origins of disinhibition, boldness and meanness. Development and Psychopathology 2: 913-38.

Pfäfflin F, Adshead G (eds) (2004) A Matter of Security: The Application of Attachment Theory to Forensic Psychiatry and Psychotherapy. Jessica Kingsley Publishers.

Richell RA, Mitchell DA, Newman C, et al (2003) Theory of mind and psychopathy: can psychopathic individuals read the 'language of eyes'? Neuropsychologia 41: 523-6

Sarkar J, Adshead G (2006) Personality disorders as disorganisation of attachment and affect regulation. Advances in Psychiatric Treatment 12: 297-305

Schore A (1996) Experience dependent maturation of a regulatory system in the orbital pre-frontal cortex and the origin of developmental psychopathology. Development and Psychopathology 8: 59-87.

Schore A (2001) The effect of early relational trauma on right brain development, affect regulation and infant mental health. Infant Mental Health Journal 22: 201-49.

Schore A (2002) Dysregulation of the right brain: a fundamental mechanism of traumatic attachment and the psychopathogenesis of posttraumatic stress disorder. Australian and New Zealand Journal of Psychiatry 36: 9-30.

Shamay-Tsoory SG, Aharon-Peretz J, Perry D (2009) Two systems for empathy: a double dissociation between emotional and cognitive empathy in inferior frontal gyrus versus ventromedial prefrontal lesions. Brain 132 (Pt 3): 617-27.

Shamay-Tsoory SG, Harari H, Aharon Peretz J, et al (2010) The role of orbitofrontal cortex in affective theory of mind deficits in criminal offenders with psychopathic tendencies. Cortex 46: 668-77.

Shonk SM, Cicchetti D (2001) Maltreatment, competency deficits, and risk for academic and behavioral maladjustment. Development and Psychopathology 37: 3-17.

Smith K, Flatley J, Coleman K, et al (2010) Home Office Statistical Bulletin: Homicides, Firearm Offences and Intimate Violence 2008/2009. TSO (The Stationery Office).

Taylor PJ, Gunn J (1999) Homicides by people with mental illness: myth and reality. British Journal of Psychiatry 174: 9-14.

van ljzendoorn M, Bakermans-Kranenburg MJ (2003) Attachment disorders and disorganised attachment: similar and different. Attachment and Human Development 5: 313-20

Weeks R, Widom CS (1998) Self-report of early childhood victimisation among incarcerated adult male felons. Journal of Interpersonal Violence 13: 346-61.

Wootton JM, Frick P, Shelton K, et al (1997) Ineffective parenting and the moderating role of callous-unemotional traits. Journal of Consulting and Clinical Psychology 65: 301-8.

Yang M, Coid J, Tyrer P (2010) Personality pathology recorded by severity: national survey. British Journal of Psychiatry 197: 193-9.
MCO answers

$\begin{array}{lllll}1 \mathrm{a} & 2 \mathrm{~d} & 3 \mathrm{a} & 4 \mathrm{a} & 5 \mathrm{a}\end{array}$ 


\section{MCOs}

Select the single best option for each question stem

1 Mentalising does not include:

a organisation of information

b empathy

c theory of mind

d self-reflective function

e perspective-taking.

2 Mentalising function has been shown to be reduced in:

a schizophrenia

b bipolar disorder

c dementia

$\mathrm{d}$ borderline personality disorder

e conduct disorder.
3 In England and Wales, violence:

a is a rare form of criminality

$\mathrm{b}$ has been rising steadily year on year

c is the same as aggression

$\mathrm{d}$ is causally associated with antisocial personality disorder

$\mathrm{e}$ is common in men.

\section{Mentalisation failures:}

a are compatible with normal psychological function

b are always found in violent offenders

c cause attacks on self and others

$\mathrm{d}$ are unrelated to psychotic disorders

e are unrelated to mood disorders
5 Mentalising function:

a can be measured using self-reflective function measures

b is improved only by mentalisation-based treatment (MBT)

c cannot be changed

$\mathrm{d}$ is a capacity made up of static factors

e does not change over the life-cycle. 